\title{
Larval regulation of adult longevity in a genetically-selected long-lived strain of Drosophila*
}

\author{
STEVEN BUCK†, MICHAEL NICHOLSON†, STEVEN DUDAS†, ROBERT WELLS†, \\ ALLAN FORCE $\dagger$, GEORGE T. BAKER III \& ROBERT ARKING †† \\ $\dagger$ Department of Biological Sciences, $\ddagger$ Institute of Gerontology, Wayne State University, Detroit, MI 48202 and \\ $\S$ Gerontological Research Center, National Institute of Aging, Baltimore, MD, USA
}

\begin{abstract}
Our previous work has shown that the major genes involved in the expression of the extendedlongevity phenotype are located on the third chromosome. Furthermore, their expression is negatively and positively influenced by chromosomes 2 and 1, respectively. In this report we show that the expression of the extended-longevity phenotype is dependent on the larval environment. A controlled chromosome substitution experiment was carried out using a strain selected for long life (L) and its parent $(\mathbf{R})$ strain. Twenty different combinations of the three major chromosomes were conducted and their longevities were determined under both high (HD) and low (LD) larval density conditions. The extended-longevity phenotype was only expressed under HD conditions. The chromosome interactions were not apparent under LD conditions. Density-shift experiments delineate a critical period for expression of the extended-longevity phenotype, extending from $60 \mathrm{~h}$ after egg laying (AEL) to $96 \mathrm{~h} \mathrm{AEL}$, during which the developing animal must be exposed to HD conditions if the extended-longevity phenotype is to be expressed. The change from HD to LD conditions is accompanied by statistically significant increases in body weight. The possible role of a dietary restriction phenomenon is examined and the implications of these findings discussed. It is now apparent, however, that the extended-longevity phenotype in Drosophila is a developmental genetic process.
\end{abstract}

Keywords: genetics of ageing, larval environment, longevity.

\section{Introduction}

Buck et al. (1993) examined a number of isogenic lines to determine which chromosome(s) were responsible for the expression of the extended-longevity phenotype when the animals were reared under high larval density $(\mathrm{HD},>50$ larvae/vial) conditions. We determined that the recessive genes necessary and sufficient for the expression of the extended-longevity phenotype in our genetically-selected $\mathrm{NDC}-\mathrm{L}_{\mathrm{A}}$ (L or 222 , using the terminology described by Buck et al. 1993) strain of Drosophila melanogaster are on the third chromosome (c3). We also showed that the expression of the extended-longevity phenotype by these $\mathrm{c} 3$ genes was dependent on the composition of the animal's first $(\mathrm{c} 1)$

\footnotetext{
*This paper is dedicated to the memory of Howard A. Schneiderman, an enthusiastic scholar, a creative administrator and a good human being.

ๆCorrespondence.
}

and second (c2) chromosomes, such that $\mathrm{c3}$ was repressed by $\mathrm{c} 2$ which was in turn repressed by $\mathrm{c} 1$, thus allowing the expression of the longevity-determinant genes on c3 (Buck et al., 1993). That analysis allowed us to identify and characterize both the additive and non-additive genetic effects. However, Curtsinger (1990) has shown that environmental effects are also very important in regulating the life span of Drosophila. Indeed, Clare and Luckinbill (1985) have previously reported the existence of a gene-environment interaction for the $\mathrm{L}$ strain, a phenomenon which was later confirmed by us (Wells et al., 1987). The mechanism of this gene-environment interaction is to date unknown. As the specific environment required by the L strain for expression of the extended-longevity phenotype was a high larval density, it would be advantageous to determine the time period in larval development during which the high density conditions exerted an effect. We believed it would also be useful to 
describe the chromosomal basis of this gene-environment interaction. Determination of the temporal sequence of events would allow further characterization of the gene-environment interaction $(\mathrm{s})$ and facilitate analysis of the development genetic mechanism $(\mathrm{s})$ underlying them.

\section{Materials and methods}

Stock construction, measurement of life span, culture conditions, use of the paraquat test to test the presence or absence of the extended-longevity phenotype, and data analysis were carried out as described by Buck et al. (1993) and Arking et al. (1991). We had constructed 27 different isogenic lines, each of which had a unique combination of $\mathrm{R}$ - and L-type $\mathrm{c} 1, \mathrm{c} 2$, and/or $\mathrm{c} 3$ chromosomes. The construction and longevity characteristics of these isogenic lines have been described (Buck et al., 1993). Replicates of a number of these isogenic lines in which the females were known to express the extended-longevity phenotype $(222,202,002)$, as well as replicates of a number of lines known to express only a shorter than normal life span $(010,011,020$, $100,110)$, a R-type life span $(000,001,012,022,112$, $200,211)$ or an intermediate-type life $\operatorname{span}(101,102$, $111,201,220$ ) were each raised under low larval density (LD) conditions. The number of animals of each genotype and sex involved in this investigation is shown in Tables 1 and 2.

The density-shift experiments were carried out at $25^{\circ} \mathrm{C}$ as follows. L strain (222) eggs were collected in timed $(0 \pm 2 \mathrm{~h})$ collections and the appropriate number were transferred to shell vials so as to initiate the cultures at either low larval density (LD, 10-12 eggs/ vial) or $\mathrm{HD}$ (50-60 eggs/vial) conditions. At timed intervals, beginning at $60 \mathrm{~h}$ after the midpoint of the egg-laying period, the animals were transferred to the reciprocal larval environment (i.e. $\mathrm{LD}$ to $\mathrm{HD}$ and vice versa). The number of vials involved in each shift is shown in Fig. 3 and the number of animals used ranged from 60 to 210 per shift, as indicated. Larvae were gently removed from their old vials and the appropriate number were transferred to a new vial. The vials were cut $2-3 \mathrm{~cm}$ from the bottom to facilitate egg and larval handling, filled with food to the cut, the top and bottom taped together and the composite vial plugged. Pupation and eclosion times were recorded. The 5-day-old adults were assayed for paraquat sensitivity, known to be a test for longevity (Arking et al., 1991) to determine the expression of the extended-longevity phenotype. Under standard conditions, the 5-day-old adult $\mathrm{L}$ type animals raised under HD conditions have a survival rate after $48 \mathrm{~h}$ exposure to $15 \mathrm{~mm}$ exogenous paraquat of 59.5 per cent $( \pm 6.6$ per cent S.E.M.), while the L-type animals raised under LD conditions have a survival rate of 5.0 per cent $( \pm 5.0$ per cent S.E.M.) (Arking et al., 1991). These differences are statistically significant. The slightly lower HD values shown in our data (Fig. 4) are due to a combination of handling effects on the larvae and pupae as well as the need for the newly transferred larvae to chew up their new food. Our control data (not shown) suggest that these secondary effects cannot, by themselves, account for the developmental changes shown in Fig. 3.

Adult body weights were obtained by weighing groups of 3-5-day-old adults. Each group was defined by the number of animals, sex, strain and larval density conditions. Between three and 19 groups of 30-50 animals each were collected and weighed for each of the eight different groups. The actual numbers of animals involved are shown in Table 4. Computation of the S.E.M. is based on the number of groups.

\section{Results}

\section{Description of longevity}

A complete description of the female longevity for the 20 different chromosome isolines tested is presented in Table 1. Inspection of the column means suggests that there does not appear to be any evidence of an extended-longevity phenotype (ELP) characterized by mean life spans of 58 days or longer under low-density conditions (Buck et al., 1993). Comparable data and conclusions for the males are presented in Table 2 . Genotypes (222, 002) which have previously been shown to express the ELP when raised under HD conditions (compare with Table 1 of Buck et al., 1993) do not exhibit the ELP when raised under LD conditions. Moreover, these genotypes are not statistically different from genotypes $(020,200)$ which do not express the ELP. There is a slight association of longer life span with homozygosity for the L-type c3; however, this association is of borderline significance only.

The previously described chromosomal interactions (see Buck et al., 1993) are also apparently modulated. The data in Tables 1 and 2 show that the repression of c3 by c2 under HD conditions is still detectable (compare 002 with 012), although its magnitude has been greatly decreased in at least some genotypes (compare 222 with 022 , Table 1 ) where only a statistically borderline repressive effect is observed. In addition, the data of Tables 1 and 2 show that $\mathrm{c} 1$ now fails to repress $\mathrm{c} 2$ in most (but not all) genotypes tested. Repression by c1 is observed only in the 112 genotype (020 vs. 220,012 vs. 112,022 vs. 222 in Table $1 ; 010$ vs. 110,011 vs. 111,020 vs. 120,012 vs. 112 , and 022 vs. 122 in Table 2). 
Table 1 Female longevity as a function of chromosome composition when reared under LD conditions

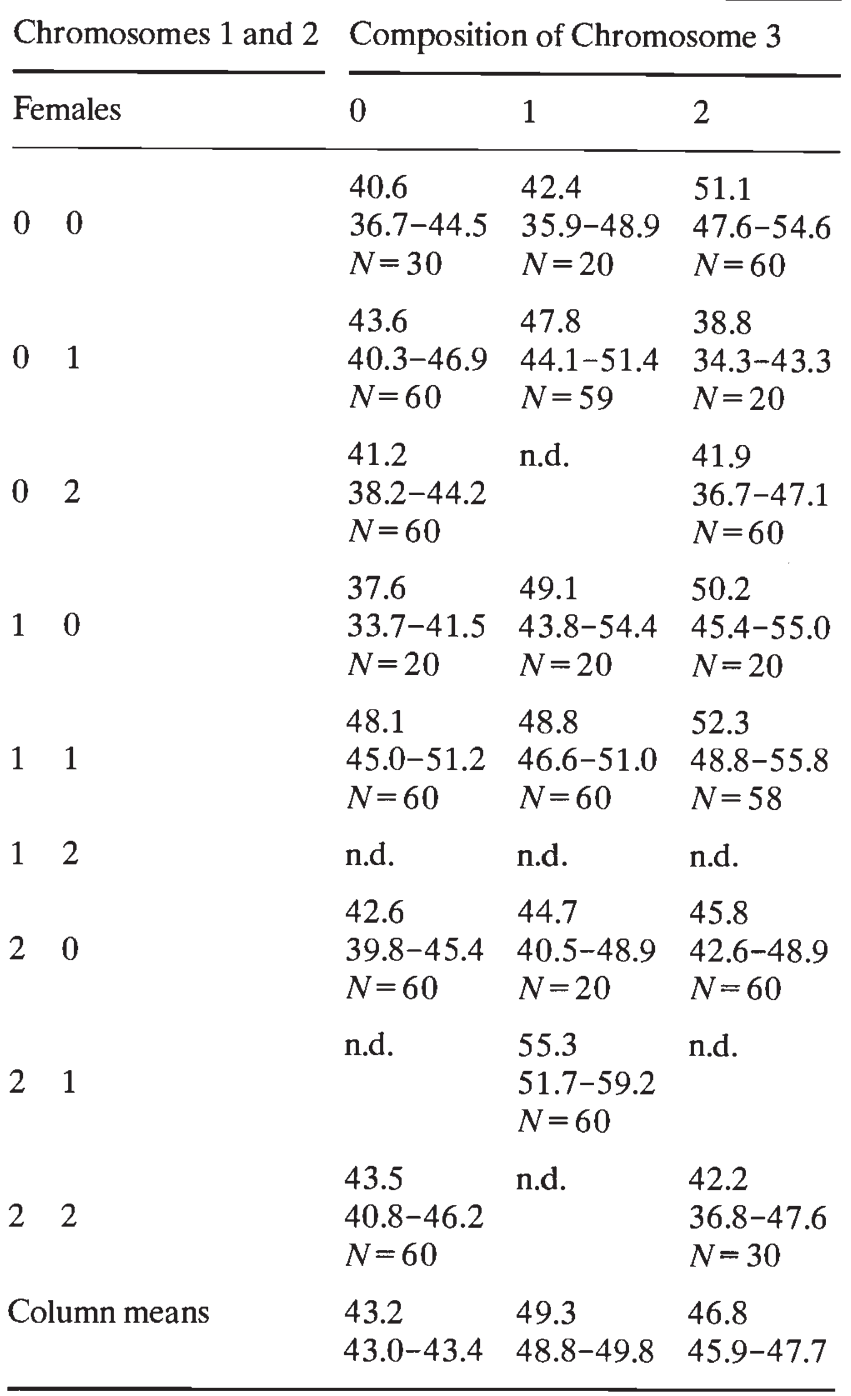

Values are the mean longevity (days), 95 per cent confidence interval and the numbers assigned.

n.d. $=$ no data, $N=$ sample size.

These observations on rearing identical genotypes under both LD and HD conditions demonstrate the effect of environmental conditions on the expression of the ELP. The LD has significantly repressed the longevity-enhancing effect of the L-type c3 (both Kolgomorov-Smirnov (K-S) and Dunnett's test, $P<0.05)$ and decreased the negative and positive effects of c2 and c1 on c3 as previously described (Buck et al., 1993). These observations are valid for both sexes.

\section{Statistical analysis of longevity}

The Kolgomorov-Smirnov non-parametric survival test (Mode et al., 1984; Zar, 1984) was employed as
Table 2 Male longevity as a function of chromosome composition when reared under LD conditions

\begin{tabular}{|c|c|c|c|c|}
\hline \multirow{2}{*}{\multicolumn{2}{|c|}{$\begin{array}{l}\text { Chromosomes } 1 \text { and } 2 \\
\text { Males }\end{array}$}} & \multicolumn{3}{|c|}{ Composition of Chromosome 3} \\
\hline & & 0 & 1 & 2 \\
\hline 0 & 0 & $\begin{array}{l}46.7 \\
44.4-49.0 \\
N=30\end{array}$ & $\begin{array}{l}46.9 \\
41.0-52.8 \\
N=20\end{array}$ & $\begin{array}{l}55.5 \\
53.2-57.8 \\
N=60\end{array}$ \\
\hline 0 & 1 & $\begin{array}{l}57.4 \\
54.3-60.5 \\
N=60\end{array}$ & $\begin{array}{l}55.8 \\
52.6-59.0 \\
N=59\end{array}$ & $\begin{array}{l}49.9 \\
45.7-54.1 \\
N=20\end{array}$ \\
\hline 0 & 2 & $\begin{array}{l}50.2 \\
47.3-53.1 \\
N=60\end{array}$ & n.d. & $\begin{array}{l}51.5 \\
47.5-55.5 \\
N=58\end{array}$ \\
\hline 1 & 0 & $\begin{array}{l}49.4 \\
48.1-50.7 \\
N=80\end{array}$ & $\begin{array}{l}48.7 \\
47.6-49.8 \\
N=40\end{array}$ & $\begin{array}{l}55.7 \\
54.8-56.6 \\
N=80\end{array}$ \\
\hline 1 & 1 & $\begin{array}{l}53.2 \\
49.8-56.6 \\
N=60\end{array}$ & $\begin{array}{l}56.0 \\
55.6-56.4 \\
N=120\end{array}$ & $\begin{array}{l}58.5 \\
54.8-62.3 \\
N=58\end{array}$ \\
\hline \multicolumn{2}{|c|}{12} & $\begin{array}{l}51.0 \\
48.2-53.8 \\
N=60\end{array}$ & n.d. & $\begin{array}{l}53.3 \\
49.8-56.8 \\
N=30\end{array}$ \\
\hline \multicolumn{2}{|c|}{ Column means } & $\begin{array}{l}51.6 \\
51.1-52.1\end{array}$ & $\begin{array}{l}54.7 \\
54.1-55.3\end{array}$ & $\begin{array}{l}54.8 \\
54.4-55.2\end{array}$ \\
\hline
\end{tabular}

Values are the mean longevity (days), 95 per cent confidence interval, and the number of animals assigned.

n.d. $=$ no data,$N=$ sample size.

previously described by Buck et al. (1993) to individually compare the survival curve of each sex of each isogenic line raised under LD conditions with the same-sex survival curve of the 000 and 222 strains raised under HD conditions. The latter are the appropriate control values for a test of the effect of larval density on longevity. This analysis allows the determination of the statistical similarity of each line relative to both controls. This analysis revealed that most, but not all, of the lines are statistically similar to the 000 control and statistically dissimilar from the 222 control line. There are, however, some exceptions. For ease of comparison, the results are shown in Fig. 1 where they have been arranged according to whether the survival curve for each particular chromosome line had a longevity which was statistically greater than, less than, identical to, or intermediate between that of the 000 and 222 controls. It can be seen that the data for females shown in Fig. 1 fall into one of two classes: a 000 type or an intermediate-type life span. The data for males (Fig. 2) show the same general classification into the same discrete life-span groups. 

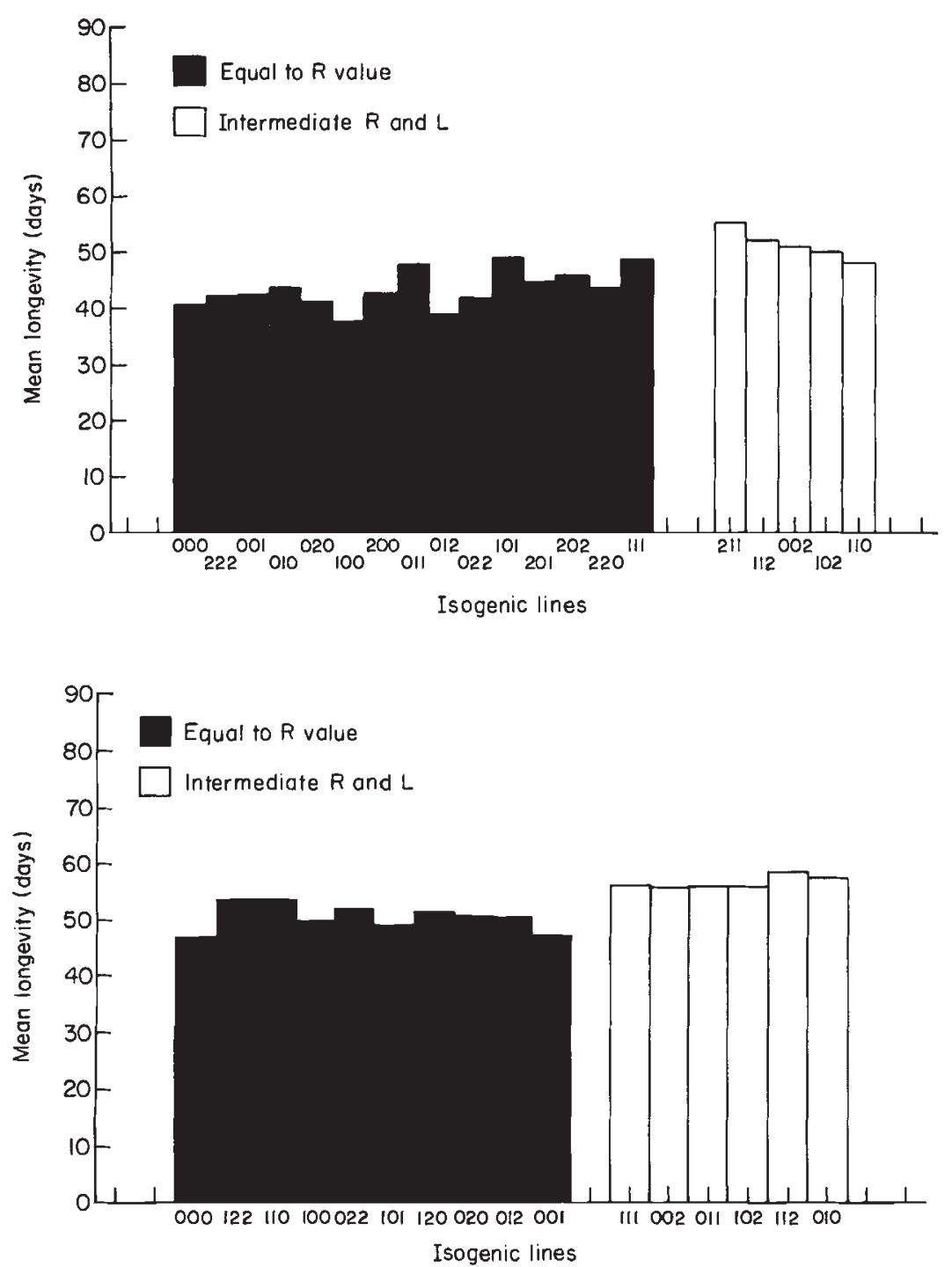

Fig. 1 The chromosome constitution and the mean life span are shown for females of each of the isogenic lines listed in Table 1. The survival curves and the mean life span of each line were compared with those of the 000-HD and 222-HD lines, and the statistical results were used to group the lines as described in the text. ( Equal to R value. ( $\square$ ) Intermediate between $R$ and $L$.

Fig. 2 The chromosome constitution and the mean life span are shown for males of each of the isogenic lines listed in Table 2. The survival curves and the mean life span of each line was compared with those of the 000-HD and 222-HD lines, and the statistical results were used to group the lines as described in the text. ( Equal to R value. ( $\square$ ) Intermediate between $R$ and L.

These conclusions were verified by using the Dunnett's multiple comparison parametric test in which multiple sample means are individually compared with a control mean and their statistical similarity/dissimilarity ascertained (Dunnett, 1955, 1964; Zar, 1984). These data were analysed using the same logic as for the non-parametric tests described above and led to the same conclusions. The two sets of conclusions are mostly compatible, the non-parametric test being the more stringent. The tests disagree in only 5 of the 38 comparisons. In no case did either test indicate that any genotype raised under LD conditions had a life span which was statistically not different from that of the 222 HD control.

\section{Magnitude of the response}

The magnitude of the change in longevity which occurs as a result of being raised under LD conditions is not a constant value across all genotypes but is dependent on chromosome composition. In Table 3, we have arranged the female genotypes according to their statistically-based HD longevity categories (see Fig. 1 of Buck et al., 1993), and have then calculated for each the alteration from their HD longevity when that same genotype was raised under LD conditions. The magnitude of the response is dependent on the HD longevity, i.e. those genotypes having the longest HD-type life span showing the largest ( 27 per cent) decrease, the two intermediate groups showing an intermediate (14 per cent) decrease, and those genotypes having the shortest HD-type life span showing no overall change in longevity. There is no observable correlation between the magnitude of the longevity change and the total number of $\mathrm{L}$ chromosomes in each genotype. There is, however, a loose association between the magnitudes of the longevity change and certain combinations of chromosomes. For example, a longevity 
Fig. 3 Determination of the critical period during which time the larvae must be exposed to HD conditions if they are to exhibit the extended-longevity phenotype. Timed 222 (L)-strain larvae were started at one density conditions, shifted to the other at the indicated time, and assayed with the paraquat test at 5 days of adult life to see if they expressed the extendedlongevity phenotype. The points represent the mean \pm S.E.M. of three independent replicate experiments. The numbers indicate the total number of vials, each containing 10 animals, used for each indicated shift. The entire experiment involved $\sim 2550$ animals exclusive of controls (not shown). $\left({ }^{6}\right.$ ) estimated time the larvae stop feeding, ( $\mathbf{4}$ ) approximate observed time of pupation, (O) LD to HD shifts, $(\bullet) H D$ to LD shifts.
Table 3 Longevity changes (in days) of different female genotypes when reared under LD conditions relative to HD conditions

LIFE SPAN CATEGORIES

\begin{tabular}{|c|c|c|c|c|c|c|c|}
\hline \multicolumn{2}{|l|}{$<$ R-type } & \multicolumn{2}{|l|}{ R-type } & \multicolumn{2}{|c|}{ Intermediate } & \multicolumn{2}{|l|}{ L-type } \\
\hline Genotype & $\Delta \mathrm{LS} \dagger$ & Genotype & $\Delta \mathrm{LS} \dagger$ & Genotype & $\Delta \mathrm{LS} \dagger$ & Genotype & $\Delta \mathrm{LS} \dagger$ \\
\hline 010 & +2.8 & 000 & -8.6 & 101 & -4.2 & 222 & -19.9 \\
\hline 011 & +5.5 & 001 & -5.4 & 102 & -9.7 & 002 & -13.2 \\
\hline 100 & -9.0 & 012 & -13.7 & 111 & -4.1 & 202 & -17.6 \\
\hline 110 & +4.7 & 022 & -8.0 & 201 & -8.1 & & \\
\hline 020 & -3.6 & 200 & -9.1 & 220 & -11.1 & & \\
\hline & & 211 & +3.1 & & & & \\
\hline Mean $\ddagger$ & $+0.1^{\mathrm{a}}$ & & $-5.8^{\mathrm{a}}$ & & $-7.4^{\mathrm{a}}$ & & $-16.9^{b}$ \\
\hline
\end{tabular}

As determined previously for HD life span (see text).

$\dagger$ Change in life span (days) from HD conditions (see Buck et al. 1993).

$\ddagger$ Categories with same superscript letter are statistically not different $(P=0.05)$.

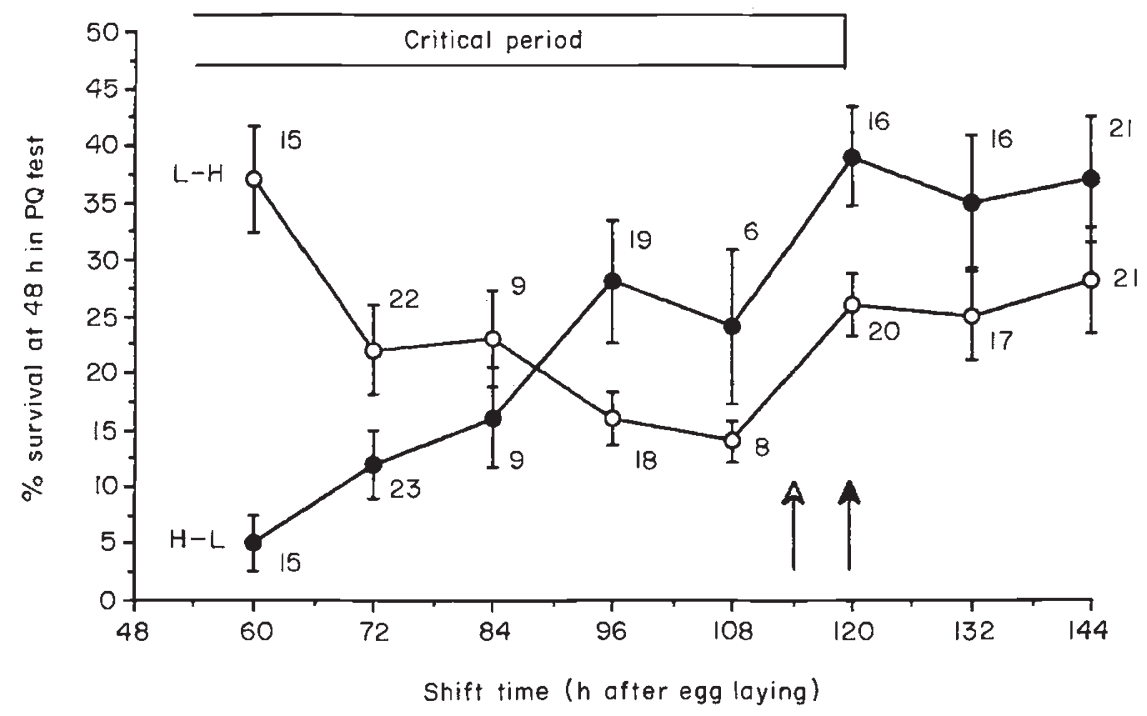

change of 11-20 days is exhibited only by genotypes which have at least one set of homozygous L chromosomes, all but one $(220)$ involving c3. A longevity change of 8-9 days is given by genotypes all but one (022) of which do not have any L-type c2. Finally, longevity changes of $0-5$ days are observed in genotypes all but one $(020)$ of which have at least two pairs of heterozygous chromosomes and/or are heterozygous for the L-type c3. Those lines that give a positive longevity change when raised under LD conditions are those which are heterozygous for c2. The functional significance of these observations is not clear.

Timing of the critical period. Developing 222 animals were shifted from $\mathrm{HD}$ to $\mathrm{LD}$ conditions (the $\mathrm{H}-\mathrm{L}$ shift), or from LD to HD conditions (the $\mathrm{L}-\mathrm{H}$ shift), at specified times during the second and third larval instars and pupal stages. These density-shifted larvae were then allowed to complete their development and were assayed at 5 days of adult life for their paraquat resistance to determine if they expressed the ELP. Animals known to display the ELP have an increased paraquat resistance, the two traits being inseparable by any of the several tests we have employed (Arking et al., 1991). The data are shown in Fig. 3. In the L-H shift protocol, the 60 -h values are significantly different from the $72-108 \mathrm{~h}$ values $\left(t_{22}=3.06, P<0.05\right)$. However, in the $\mathrm{H}-\mathrm{L}$ shift, $120-144 \mathrm{~h}$ values are statistically not dissimilar from each other $\left(t_{35}=0.34\right.$, $P>0.05$ ) but the $120 \mathrm{~h}$ value is statistically different 
from the 108 -h value $\left(t_{20}=1.74, P<0.05\right)$, which in turn is statistically not dissimilar from the $96-\mathrm{h}$ value $\left(t_{23}=0.34, P>0.05\right)$. The $96-\mathrm{h}$ values are statistically dissimilar from the $72-$ and $60-\mathrm{h}$ values $\left(t_{31}=3.23\right.$, $P<0.05)$. The increase in paraquat resistance observed in the $\mathrm{L}-\mathrm{H}$ shift between $120-144 \mathrm{~h}$ is an apparent anomaly, given the almost linear change in paraquat resistance observed in the $\mathrm{H}-\mathrm{L}$ shift. We interpret the increase as being only an apparent one actually caused by lower than expected values for the 96- and 108-h shifts. Such a situation might arise if the newly-transferred L-H larvae had a transient but effective surplus of food on being shifted into a new vial at 96 and $108 \mathrm{~h}$, thereby in effect extending a LD status for some variable period in time. Experiments in which 96-h larvae were shifted into vials containing used food and gave higher paraquat survival values than did their sibs shifted into vials containing new food are compatible with this interpretation (data not shown). The important aspects of the data are not ambiguities in the middle of the period, however, but rather the statistically significant decrease in paraquat resistance induced by the $\mathrm{L}-\mathrm{H}$ shift at $60 \mathrm{~h}$ which signals the beginning of the critical period, and the statistically significant plateau in the $\mathrm{H}-\mathrm{L}$ shift beginning at $120 \mathrm{~h}$ which signals the end of the critical period (Suzuki, 1970). Taken together, these data define the existence of a critical period in larval development which begins no later than $60 \mathrm{~h}$ after oviposition and which ends no earlier than $120 \mathrm{~h}$ after oviposition, during which the developing larva must be exposed to HD conditions if an ELP is to be expressed.

Density-dependent changes in adult body weight. Larval density conditions affect adult body weight. The data of Table 4 show that, in both sexes and strains, the LD body weight is higher than the HD body weight. Females are more responsive to this change in developmental conditions than are males, and 222 (L) strain animals are more sensitive than are 000 (R) strain animals. The differences in body weight of the 000 males on LD or HD are not statistically significant. The other three genotype/sex combinations, however, do show statistically significant differences in body weight $(P<0.01)$. These differences are associated with an alteration in adult life span. For the same sex and larval density, there is no statistically significant difference in body weight between $\mathrm{R}$ - and L-strain animals of the same sex, with the exception of the LD males. Thus, interstrain differences in life span at the same larval density conditions cannot simply be attributed to differences in body weight.
Table 4 Relationship between larval density, adult body weight and adult longevity

\begin{tabular}{|c|c|c|c|c|c|}
\hline Strain & Sex & Density & $N$ & $\begin{array}{l}\text { Body weight } \\
\text { mean (S.E.M.), } \\
\text { mg }\end{array}$ & $\begin{array}{l}\text { Longevity } \\
\text { in days }\end{array}$ \\
\hline \multirow[t]{2}{*}{$\mathrm{L}$} & q & HD & $\begin{array}{l}618 \\
(17)\end{array}$ & $\begin{array}{r}1.13^{\mathrm{a}} \\
(0.03)\end{array}$ & $62.1^{\mathrm{e}}$ \\
\hline & q & $\mathrm{LD}$ & $\begin{array}{c}234 \\
(6)\end{array}$ & $\begin{array}{r}1.40^{\mathrm{b}} \\
(0.02)\end{array}$ & $42.2^{f}$ \\
\hline \multirow[t]{2}{*}{$\mathrm{L}$} & 0 & HD & $\begin{array}{l}639 \\
(13)\end{array}$ & $\begin{array}{r}0.77^{\mathrm{c}} \\
(0.02)\end{array}$ & $66.2^{\mathrm{g}}$ \\
\hline & 0 & $\mathrm{LD}$ & $\begin{array}{l}209 \\
(4)\end{array}$ & $\begin{array}{r}0.90^{\mathrm{d}} \\
(0.04)\end{array}$ & $53.3^{\mathrm{h}}$ \\
\hline \multirow[t]{2}{*}{ R } & \& & HD & $\begin{array}{l}753 \\
(19)\end{array}$ & $\begin{array}{r}1.30^{\mathrm{a}} \\
(0.03)\end{array}$ & $49.2^{\mathrm{i}}$ \\
\hline & \& & LD & $\begin{array}{l}199 \\
(5)\end{array}$ & $\begin{array}{c}1.51^{\mathrm{b}} \\
(0.07)\end{array}$ & $40.6^{f}$ \\
\hline \multirow[t]{2}{*}{ R } & c & HD & $\begin{array}{l}677 \\
(14)\end{array}$ & $\begin{array}{r}0.76^{\mathrm{c}} \\
(0.02)\end{array}$ & $52.3^{\mathrm{j}}$ \\
\hline & c & LD & $\begin{array}{l}142 \\
(3)\end{array}$ & $\begin{array}{r}0.79^{c} \\
(0.06)\end{array}$ & $46.7^{\mathrm{h}}$ \\
\hline
\end{tabular}

$N=$ number of animals assayed (number of groups).

Entries with same superscript letter are statistically not different from one another $(P>0.05)$; entries with different superscript letters are statistically different from one another $(P<0.05)$.

Longevity data taken from Tables 1 and 2 .

\section{Discussion}

Larval density is known to affect life span in wild strains of Drosophila melanogaster (Miller \& Thomas, 1958; Lints \& Lints, 1971; Economos \& Lints, 1984a, b; Zwaan et al., 1991; 1992). Our selected strains, which were originally derived from wild-caught flies, also exhibit an obvious larval density-dependent longevity (Clare \& Luckinbill, 1985; Wells et al., 1987). Previous studies have delineated the chromosomal basis for the extended-longevity phenotype (Buck et al., 1993), wherein the c3 is primarily involved in the expression of the ELP which in turn is positively and negatively regulated in its expression by $\mathrm{c} 1$ and $\mathrm{c} 2$, respectively.

\section{Environmental effects on phenotype expression}

The results show that the extended-longevity phenotype virtually disappears when the longer-lived strains are raised under LD conditions. The extended-longevity phenotype is strikingly density-dependent (Fig. 1; also compare Table 1 of this paper to Table 1 of Buck et al., 1993). The effect of larval density is observed on 
most but not all genotypes. For example, the LD has effects on the mean life span of non-long-lived genotypes (Table 3 ) ranging from no alteration in mean life span $(010,011,100,110,020)$ to a mean decrease ranging from $5.8(000,001,012,022,200,211)$ to 7.4 days $(101,102,111,201,220)$. It has been previously shown that LD conditions decreased the life span in adults of several different wild-type strains by about this amount (Miller \& Thomas, 1958; Lints \& Lints, 1971; Zwaan et al., 1991; 1992). Thus there appears to be a generalized response of Drosophila life span to larval density which alters adult longevity by 5-7 days.

What is more important is the response of the three extended longevity genotypes $(222,002,202)$ to $\mathrm{HD}$. These animals increase their mean LD life span by 16.9 days (Table 3 ). This response is statistically different $(P<0.05)$ from that of the other genotypes. Therefore, any investigation of the mechanisms responsible for this environmental manipulation of adult longevity should focus on these genotypes, lest the results be confounded with the more general and less dramatic response of the species as a whole. The data indicate that as both the 222 and the 202 genotypes respond equally well to LD conditions, the primary genetic elements required for the transduction of the environmental signals into genetic signals cannot be located on the L-type $c 2$. They apparently must be located on the L-type c3 and/or c1. Mutational analysis should be able to settle this question.

\section{Larval development and adult longevity}

Most previous studies on this topic have shown that HD conditions slow down the development rate (Lints \& Lints, 1971; Boetella et al., 1985), the theoretical assumption being that slower development somehow led to the long life span. However, Yonemura et al. (1991) have demonstrated that extended longevity is associated with a faster developmental time in their strains. We are presently investigating this problem. Our ongoing studies (Buck \& Arking, unpublished data) indicate that the strains can be arranged from fastest to slowest development time in the following sequence L-LD $>$ R-LD $\gg$ L-HD $>$ R-HD. Therefore, development time alone cannot be the casual factor in determining adult longevity, because neither the fastest developing animals (L-LD) nor the slowest developing animals ( $\mathrm{R}-\mathrm{HD})$ are the longest lived. There is no apparent simple relationship between the two variables in our strains.

Economos \& Lints (1985) have shown the existence of a biphasic, as opposed to a linear, relationship between larval growth rate and adult life span. This suggests the existence of a more complex arrangement between the two variables. We have shown elsewhere that the manipulation of the pre-adult develoment time by the use of different temperature regimens has no effect on adult life span (Arking et al., 1988), an observation which has been recently confirmed by Zwaan et al. $(1991 ; 1992)$ using either temperature or nutrition as the independent variable. Thus it is not simply the developmental time per se which is important but rather some integrated response of the different genotypes to the same environmental conditions. This conclusion is consistent with that of Economos \& Lints (1985) who found that life span and developmental time are not coupled. The apparent correlations between these two variables may not be evidence of a causal relation but rather the result of coincidental covariation. For example, our data suggest that it is not the developmental time which is important but rather the environmental conditions in which that development took place.

We have no definitive information regarding the specific mechanisms involved in the larval densitydependent alteration of adult life span. However, the fact that adult life span can be modulated by larval density suggests that adult life span must be regarded as the result of temporally specific developmentalgenetic processes. This observation is consistent with the interpretation of our biomarker experiments (Arking \& Wells, 1990; Arking et al., 1991) which showed that the molecular genetic mechanisms regulating adult longevity are associated with events that occur during or prior to the first week of adult life.

There are at least four plausible explanations for the role of larval HD in determining adult longevity. Firstly, it may simply be a pleiotropic effect of stress. It has long been known that a variety of mild stresses may actually improve physiological functions to abovenormal levels (hormeosis; Sacher, 1977). In Drosophila, a variety of environmental stresses affects the functioning of the heat shock protein $(h s p)$ genes and, through them, a variety of physiological systems (Ashburner, 1979). We have no information on the role of $h s p$ genes in the expression of the extended-longevity phenotype in our strains.

Secondly, the larval HD conditions might give rise to the presence in the food of higher titres of chemical substances (excreted or otherwise formed) not present in LD conditions, and which might act as inducers of gene action in the developing larvae. A secondary assumption would be that these induced changes in gene expression would then have profound effects in later stages of the life cycle. The existence of such chemicals has been demonstrated in several organisms, including Drosophila (Botella et al., 1985; Becker et al., 1990; Crowl \& Covich, 1990; Pritsos et al., 1990; 
Storz et al., 1990). We know that the chemical composition of the HD food appears to be somewhat different in its $p \mathrm{H}$ and reducing ability from that of the LD food (data not shown). We also know that there exist early and obvious changes in specific mRNA levels between R-HD and L-HD strains and between L-HD and L-LD animals (Dudas \& Arking, 1990 and unpublished data).

Thirdly, it may simply be an example of differential mortality wherein HD conditions bring about the death of the relatively unfit individuals which also have a low longevity. This, however, is not the case as the overall (egg to adult) viability for the L-strain is 73.3 per cent under LD conditions and 71.9 per cent under HD conditions.

Fourthly, it may be another example of the lifeextending effects of dietary restriction. Such a regimen has long been known to improve a number of physiological functional capabilities as well as life span in vertebrates (Ingram et al., 1991). Austad (1989) has shown that dietary restriction is effective in extending adult life span in adult spiders. David et al. (1971) failed to find any evidence to suggest that dietary restriction in Drosophila adults enhanced the adult life span. However, it was recently reported that Drosophila raised on either rich or poor larval food and selected for increased body weight at eclosion, had a shorter life span and higher earlier fecundity than did those lines raised under similar conditions and selected for decreased body weight at eclosion (Hillesheim \& Stearns, 1992). Table 4 shows that HD larval conditions are associated with a decrease in adult body weight and an increase in adult life span. These observations suggest that dietary restriction might possibly be the underlying mechanism by which gene expression is altered. Indeed, there is evidence of altered gene expression in vertebrate systems subjected to caloric restriction (Richardson et al., 1985). If so, then the difference between our results and those of David et al. (1971) might reside in the fact that dietary restriction would be expected to be more effective in the mitotically-active larval instars than in the virtually postmitotic adult stages. Drosophila larvae are not capable of successfully completing development to the adult stage until they have moulted into the third larval instar and have reached a critical mass of about $0.3 \mathrm{mg}$ dry weight (Ashburner, 1989; also see Bakker, 1961). The $\mathrm{HD}$ critical period shown in Fig. 3 coincides with the third larval instar. It has also long been known that the major portion of imaginal disc growth takes place during this period of time (Church \& Robertson, 1969; Nothiger, 1972; Bryant, 1987). The body weight data shown in Table 4 support the view that there is some relationship between body weight and the expression of the ELP. Economos \& Lints (1984a, b, 1985) have examined the relationship between growth rate and life span in a normal-lived wild-type strain. They have concluded that the maximal life span in their strain is associated with submaximal rates of growth. Given their observed biphasic relationship, they concluded that feeding larvae less than a certain critical amount of yeast ( $\sim 140 \mathrm{mg}$ yeast per 120 eggs) would lead to a shortened adult life span, presumably because of pathological effects associated with malnourishment. Feeding larvae more than this critical amount of yeast resulted in a shorter lived but larger animal, as judged by body weight, cell size and cell number. These results led them to suggest that dietary restriction might be operative in their Drosophila. Our manipulation of larval density seems to have achieved the same goal as yeast restriction has in their system. Experiments designed to further explore this possibility in our strains are currently in progress and will be described elsewhere.

The NDC-L (222) strain that we are now using was derived from the $\mathrm{R}(000)$ strain by selection under HD conditions (Arking, 1987). The selection conditions used were such as to simultaneously select for rapidly developing, late-reproducing, long-lived adults. The HD condition was not essential to the expression of the extended-longevity phenotype as our DC- $\mathrm{L}$ strain showed a substantial increase in adult longevity even though it was selected under LD conditions (Arking, 1987). Unfortunately, the DC-L strain no longer exists (Arking, 1987b) and cannot be examined. The fact of its existence, however, means that the expression of extended longevity in our selected strain cannot be attributed solely to caloric restriction. Both $\mathrm{R}$ and $\mathrm{L}$ strains respond to $\mathrm{LD}$ conditions; however, the response is governed by their chromosomal composition and the specific selection scheme used. Presumably, different selection schemes might have allowed the population to adopt different mechanisms to yield the same phenotype (e.g. Hoffman \& Parsons, 1992; Rose et al. 1992).

The effects of larval density on the biochemical composition of the 222 and 000 adults is currently under investigation in this laboratory. We believe that the Drosophila system will allow us to genetically dissect the genetic and environmental factors that are critically involved in the regulation of longevity in $\mathrm{L}$ and $\mathrm{R}$ strain animals.

\section{Conclusions}

We have demonstrated that extended longevity in our Drosophila strains is the outcome of a developmental genetic process. The increase in the mean longevity of 
the $\mathrm{L}$ strain adult animals induced by the larval $\mathrm{HD}$ conditions is correlated with changes in other larval and adult behavioural and physiological traits. These changes appear to arise from developmental changes that manifest themselves during the third larval instar. The ontogenetic mechanisms that might comprise and regulate this developmental switch are the subject of ongoing investigations.

\section{Acknowledgements}

We would like to thank Mr Chris Kolde and Ms Rehka Patel for their efforts and assistance during the construction of the six isogenic lines. We also thank Ms Susan Lagrou, Ms Vesna Evkoska and Mr Leonard Karadimas for their assistance during the lifespan measurements, and Ms Christine Neslund for her general technical assistance. The comments of $\mathrm{T}$. E. Johnson on an earlier version of this manuscript were very helpful and are appreciated. This research was supported by the WSU Institute of Gerontology, by a WSU-NIH Biomedical Research Support grant to R. A. and by a WSU President's Excellence Award to R.A.

\section{References}

ASHBURNER, M. 1979. The induction of gene activity in Drosophila by heat shock. Cell, 17, 241-254.

ASHBURNER, R. 1987a. Successful selection for increased longevity in Drosophila: analysis of the survival data and presentation of a hypothesis on the genetic regulation of longevity. Exp. Gerontol., 22, 199-220.

ARKING, R. 1987 b. Letter to the editor. Exp. Gerontol.,22, 223-226.

ARKING, R., BUCK, S., BERRIOS, A., DWYER, S. AND BAKER, G. T., III. 1991. Elevated paraquat resistance can be used as a bioassay for longevity in a genetically based long-lived strain of Drosophila. Devel. Genetics, 12, 362-370.

ARKING, R., BUCK, S. WELLS, R. A. AND PRETZLAFF, R. 1988. Metabolic rates in genetically based long lived strains of Drosophila. Exp. Gerontol., 23, 59-76.

ARKING, R. AND wELLS, R. A. 1990 . Genetic alteration of normal aging processes is responsible for extended longevity in Drosophila. Devel. Genetics, 11, 141-148.

AUSTAD, S. N. 1989. Life extension by dietary restriction in the bowl and doily spider, Frontilnela pyramitela. Exp. Gerontol., 24, 83-92.

BAKKER, K. 1961. An analysis of factors which determine success in competition for food among larvae of Drosophila melanogaster. Arch. Neerland. Zool., 14, 200-281.

BECKER, J., MEZGER, V., COURGEON, A.-M. AND BEST-BELPOMME, M. 1990. Hydrogen peroxide activities immediate binding of a Drosophila factor to DNA heat-shock regulatory element in vivo and in vitro. Eur. J. Biochem., 189, 553-558.

BOETELlA, L. M., MOYA, A., GONZALEZ, M. C. AND MENSUA, J. L. 1985. Larval stop, delayed development and survival in overcrowded cultures of Drosophila melanogaster: effect of urea and uric acid. J. Insect Physiol., 31, 179-185.

BRYANT, P. J. 1987. Experimental and genetic analysis of growth and cell proliferation in Drosophila imaginal discs. In: Loomis, W. F. (ed.) Genetic Regulation of Development. Alan R. Liss, New York, pp. 339-372.

BUCK, S., WELLS, R. A., DUDAS, S. P., BAKER, G. T., III AND ARKING, R. 1993. Chromosomal localization and regulation of the longevity determinant genes in a selected strain of Drosophila melanogaster. Heredity 71, 11-22.

CHURCH, R. AND ROBERTSON, F. 1969. A biochemical study of the growth of Drosophila. J. Exp. Zool., 162, 337-352.

CLARE, M. AND LUCKINBILL, L. 1985. The effects of geneenvironment interaction on the expression of longevity. Heredity, 55, 19-29.

CROWL, T. A. AND COVICH, A. P. 1990. Predator-induced lifehistory shifts in a freshwater snail. Science, 247, 949-951.

CURTSINGER, J. 1990. "Genetic and environmental components in variance of longevity in Drosophila males". Talk presented at 43rd annual meeting of Gerontology Society of America, 18 November.

DAVID, J., VAN HERREWEGE, J. AND FOUILLER, R. 1971. Quantitative underfeeding of Drosophila: effects on adult longevity and fecundity. Exp. Gerontol., 6, 249.

DUDAS, S. P. AND ARKING, R. 1990. Genetic expression in longlived strains of Drosophila. Gerontologist, 30, 115A. (abstract).

DUNNETT, C. w. 1955. A multiple comparison procedure for comparing several treatments with a control. Am. Stat. Assoc. J., 50, 1096-1121.

DUNNETT, C. w. 1964. New tables for multiple comparisons with a control. Biometrics, 20, 482-491.

ECONOMOS, A. C. AND LINTS, F. A. 1984a. Growth rate and life span in Drosophila. $i$. Methods and mechanisms of growth rate. Mech. Ageing Devel., 27, 1-13.

ECONOMOS, A. C. AND LINTS, F. A. 1984b. Growth rate and life span in Drosophila. iii. Effect of body size and developmental temperature on the biphasic relationship between growth rate and life span. Mech. Ageing Devel., 27, $153-160$.

ECONOMOS, A. C. AND LINTS, F. A. 1985. Growth rate and life span in Drosophila. iv. Role of cell $\mathrm{z}=$ size and cell number in the biphasic relationship between life span and grow th rate. Mech. Ageing Devel., 32, 193-204.

HILLESHEIM, E. AND STEARNS, S. C. 1992. Correlated responses in life-history traits to artificial selection for body weights in Drosophila melanogaster. Evolution, 46, 745-752.

HOFFMAN, A. A. AND PARSONS, P. A. 1993. Selection for adult dessication resistance in Drosophila melanogaster. Fitness components, larvae resistance and stress correlations. Biol. J. Linn. Soc., in press.

INGRAM, D., BAKER, G. T. III, AND N. SHOCK, 1991. Potential for Nutritional Modulation of Aging Processes. Food and Nutrition Press, Westport, CT.

LINTS, F. A. AND LINTS, C. V. 1971. Influence of preimaginal environment on fecundity and ageing in Drosophila melanogaster hybrids. ii. Developmental speed and life span. Exp. Gerontol., 6, 427-445.

MILLER, R. S. AND THOMAS, J. L. 1958. The effects of larval 
crowding and body size on the longevity of adult Drosophila melanogaster. Ecology, 39, 118-125.

MODE, C. J., ASHLEIGH, R. D., ZAWODNIAK, A. AND BAKER, G. T. III. 1984. On statistical tests of significance in studies of survivorship in laboratory animals. J. Gerontology, 39, $36-42$.

NOTHIGER, R. 1972. The larval development of imaginal discs. In Ursprung, $\mathrm{H}$. and Nothiger, R. (eds) The Biology of Imaginal Discs: Results and Problems in Cell Differentiation, vol. 5. Springer-Verlag, New York, Chap. 1.

PRITSOS, C., AHMAD, S., ElliotT, A. AND PARDINI, R. 1990. Antioxidant enzyme level response to prooxidant allelochemicals in larvae of the Southern armyworm moth, Spopdeptera eridania. Free Rad. Res. Commun., 9, 127-133.

RICHARDSON, A., ROBERTS, M. S. AND RUTHERFORD, M. S. 1985. Aging and gene expression. Rev. Biol. Res. Aging, 2, 395-419.

ROSE, M. R., VU, L. N., PARK, S. U. AND GRAVES, J. L. JR. 1992. Selection on stress resistance increases longevity in Drosophila melanogaster. Exp. Gerontol., 27, 241-250.

SACHER, G. A. 1977. Life table modification and life prolongation. In Finch, C. E. and Hayflick, L. (eds) Handbook of the Biology of Aging. Van Nostrand Reinhold, New York.
STORZ, G., TARTAGLIA, S., FARR, S. AND AMES, B. 1990. Bacterial defenses against oxidative stress. Trends Genetics, 6, 363-368.

SUZUKI, D. T. 1970 . Temperature-sensitive mutations in Drosophila melanogaster. Science, 170, 695-706.

WELLS, R. A., BUCK, S., ALI, R., MARZOUQ, O. AND ARKING, R. 1987. Localization of the longevity genes in $D$. melanogaster. Gerontologist, 27, 149A (abstract).

YONEMURA, I., MOTOYAMA, T., HASEKURA, H. AND BOETTCHER, B. 1991. Relationship between genotypes of longevity genes and developmental speed in Drosophila melanogaster. Heredity, 66, 143-149.

ZAR, J. H., 1984. Biostatistical Analysis, 2nd edn. PrenticeHall, Englewood Cliffs, New Jersey.

ZWAAN, B., BIJLSMA, R. AND HOEKSTRA, R. 1991a. On the developmental theory of ageing. $i$. Starvation resistance and longevity in Drosophila melanogaster in relation to preadult breeding conditions. Heredity, 66, 29-39.

ZWAAN, B., BIJLSMA, R. AND HOEKSTRA, R. 1992. On the developmental theory of ageing. ii. the effect of developmental temperature on longevity in relation to adult body size in D. melanogster. Heredity, 68, 123-130. 